\title{
ACUTE APPENDICITIS IN PREGNANCY- CLINICAL FEATURES, DIAGNOSTIC MODALITIES AND MANAGEMENT
}

\author{
Kiran Silwal1', Sunilkumar Singh Salam², Laitonjam Chinglensana3, Yumnam Priyabarta4, Soibam Jaya Leima ${ }^{5}$, \\ Manoharmayum Birkumar Sharma ${ }^{6}$
}

${ }^{1}$ Resident, Department of General Surgery, Regional Institute of Medical Sciences, Imphal, Manipur, India. ${ }^{2}$ Assistant Professor, Department of General Surgery, Regional Institute of Medical Sciences, Imphal, Manipur, India. ${ }^{3}$ Assistant Professor, Department of General Surgery, Regional Institute of Medical Sciences, Imphal, Manipur, India. ${ }^{4}$ Assistant Professor, Department of Radiodiagnosis, Regional Institute of Medical Sciences, Imphal, Manipur, India. ${ }^{5}$ Senior Resident, Department of General Surgery, Regional Institute of Medical Sciences, Imphal, Manipur, India. ${ }^{6}$ Professor, Department of General Surgery, Regional Institute of Medical Sciences, Imphal, Manipur, India.

\section{ABSTRACT}

\section{BACKGROUND}

Acute appendicitis is the most common non-obstetric surgical emergency during pregnancy accounting for 1 in 1500 deliveries with preponderance during the second trimester. Attention of the surgeons is often distracted by the pregnant status and requires a high index of suspicion in a labouring patient with less prominent peritoneal findings and atypical laboratory values.

With the objective of determining the presenting features, imaging confirmation and appropriate management, a study is conducted on appendicitis during pregnancy.

\section{MATERIALS AND METHODS}

A descriptive study was carried out in the Department of Surgery, Regional Institute of Medical Sciences (RIMS), Imphal, Manipur, for a period of 2 years from September 2015 to August 2017 on 17 patients admitted with acute appendicitis during pregnancy under variables including age, weeks of pregnancy, symptoms, duration, presenting signs, palpable mass, total leucocyte count, ultrasound findings, treatment received, outcome, length of stay and histopathological findings. Continuous measurements were presented on Mean \pm SD (Min - Max) and results on categorical measurements were presented in number (\%). SPSS version 21 was used for the analysis.

\section{RESULTS}

Age group of 18 - 29 years (76.5\%) with the mean $26.88 \pm 5.28$ was most affected; $82.4 \%$ were urban middle class, $58.8 \%$ during the second trimester followed by first (29.4\%) and third (11.8\%) trimester respectively. Right Iliac Fossa (RIF) tenderness was present in 16 patients (94.1\%), rebound tenderness in 11 patients $(64.7 \%)$ and 6 patients (35.3\%) underwent appendicectomy. The hospital stay of the patients was of mean duration of $5.65 \pm 1.7$ days.

\section{CONCLUSION}

Acute appendicitis in pregnancy remains a challenge to the evaluating surgeon. The potential hazard of the ionising radiation limits the choices of imaging during pregnancy. Even though ultrasonography has proven to be accurate in the first and second trimester, sensitivity is less and it is technically difficult to perform in the late second and third trimester. Further, judicious imaging (CT/ MRI) may avoid a negative appendicectomy but carries significant maternal and foetal morbidity. Early diagnosis and surgical intervention reduce the morbidity and mortality from the disease.

\section{KEY WORDS}

Acute Appendicitis, Rebound Tenderness, Pregnancy, Appendicectomy.

HOW TO CITE THIS ARTICLE: Silwal K, Salam SS, Chinglensana L, et al. Acute appendicitis in pregnancy- clinical features, diagnostic modalities and management. J. Evolution Med. Dent. Sci. 2018;7(34):3734-3738, DOI: 10.14260/jemds/2018/839

\section{BACKGROUND}

Acute appendicitis is one of the most frequent indications for abdominal surgery. Since Reginald Fitz presented the first comprehensive description of appendicitis and advocated early surgical removal of the appendix in 1886, appendicitis has been recognised as one of the most common causes of the acute abdomen worldwide.1,2 Appendicitis is the most common general surgical problem encountered during

'Financial or Other Competing Interest': None

Submission 02-07-2018, Peer Review 03-08-2018,

Acceptance 09-08-2018, Published 17-08-2018.

Corresponding Author:

Dr. Laitonjam Chinglensana,

Singjamei Thongam Leikai, Lane 3,

Imphal West-795001, Manipur, India.

E-mail: chinglensana@rediffmail.com

DOI: $10.14260 /$ jemds $/ 2018 / 839$ pregnancy. ${ }^{3}$ Appendicitis occurs most frequently in the second and third decades of life and pregnancy occurs mostly during the same period, which may be one of the reasons for being the most common non-obstetric surgical emergency in pregnancy. The incidence ranges from 0.06 to 0.1 percent or 1 in 1500 deliveries. ${ }^{4,5,6}$ However, pregnant women appear to be less likely to have appendicitis than age-matched nonpregnant women. ${ }^{7}$

There is a slightly higher rate of appendicitis in the second trimester than in the first and third trimesters or postpartum. ${ }^{7}$ Infected appendix appears to be more likely to rupture during pregnancy, especially in the third trimester, possibly because of delay in diagnosis and intervention. 8,9 Signs and symptoms of appendicitis are also slightly different during pregnancy. Right lower quadrant pain is the most common symptom of appendicitis and should alert the physician caring for the pregnant patient to strongly consider this diagnosis. Although, the location of the appendix 
migrates a few centimetres cephalad with the enlarging uterus, ${ }^{10,11,12}$ the most common symptom of appendicitis i.e. right lower quadrant pain occurs close to McBurney's point in the vast majority of pregnant women, regardless of the stage of pregnancy.6,12,13

The diagnosis of acute appendicitis in a labouring patient is especially difficult and requires a high index of suspicion. Labour can be associated with pain that may be lateralised, fever if chorioamnionitis is present, leukocytosis and vomiting. The physiologic changes of pregnancy can confound the diagnosis. In particular, the normal pregnant woman's white blood cell count ranges from 6000 to $16,000 \mathrm{cell} / \mathrm{mm}^{3}$ in the first and second trimesters, and may rise as high as 20,000 to 30,000 cells $/ \mathrm{mm}^{3}$ during labour. ${ }^{4}$ Thus, leukocytosis can be a normal finding in pregnant women. Pregnant women with pyuria may be treated for urinary tract infection and forego further investigation, in which case the actual diagnosis of appendicitis may be delayed. It is important to remember the inflamed appendix is often in close proximity to the bladder and ureter, as a result microscopic haematuria and pyuria are found in acute appendicitis. Peritoneal findings may be less prominent than in non-pregnant women, because the gravid uterus lifts and stretches the anterior abdominal wall away from the inflamed appendix.14,15,16 Since direct contact between the area of inflammation and parietal peritoneum is impeded, there is less muscle response or guarding. The gravid uterus may also prevent contact between the omentum and the inflamed appendix.

As in non-pregnant patients, diagnostic imaging should be performed in patients suspected of having appendicitis when the diagnosis is unclear after assessment of presenting complaints, physical examination and laboratory results.3,5,17 Thus, virtually all pregnant women will have an imaging study. The initial imaging modality of choice for diagnostic imaging of the appendix in pregnancy is graded compression ultrasonography. Ultrasound allows for visualisation of the uterus, placenta and ovaries, and thus can be used to exclude some other causes of right lower quadrant pain. Appendicitis is diagnosed if a non-compressible blind-ended tubular structure is visualised in the right lower quadrant with a maximal diameter greater than $6 \mathrm{~mm} .{ }^{18,19}$

If clinical findings and ultrasound are inconclusive or in centres where experience with sonographic examination of the appendix is limited, magnetic resonance imaging is recommended where available, because it avoids foetal exposure to ionising radiation and performs well in diagnosis of lower abdominal/ pelvic disorders. Computed tomography is suggested only when magnetic resonance imaging is not available, given its proven value in non-pregnant individuals.

The decision to proceed to laparotomy should be based upon the clinical findings, diagnostic imaging results and clinical judgement. Laboratory tests are not particularly useful other than to rule out in an alternate diagnosis. Delaying intervention for more than 24 hours increases the risk of perforation. ${ }^{8,20}$ It is not appendicectomy that kills, but the delay in appendicectomy that kills. When the diagnosis is relatively certain, appendicectomy is recommended through a transverse incision at McBurney's point or more commonly over the point of maximal tenderness. ${ }^{12,13}$
Pregnancy related complications are frequent, particularly when surgery was performed in the first or second trimester. No pregnancy complications were observed in women who underwent appendicectomy in the third trimester. The long-term prognosis for women who undergo appendicectomy during pregnancy seems to be good. Such women do not appear to be at increased risk for infertility or other complications. ${ }^{21}$

This study aims to better understand the range of clinical presentation and the effectiveness of ultrasonography in the local population as similar study has not been conducted earlier in this setup. This will aid to correctly diagnose the condition and reduce the rate of negative appendicectomy and further prevent the complications associated with negative appendicectomy preventing morbidity and mortality among pregnant woman and the developing foetus.

\section{MATERIALS AND METHODS}

The descriptive study population consists of consecutive patients with acute appendicitis in various weeks of pregnancy during a period of two years from September 2015 to August 2017 admitted in the surgical wards of RIMS, Imphal, Manipur. 17 pregnant patients admitted with a diagnosis of appendicitis during the duration of study were included under variables like age, settlement, socioeconomic status, trimester of pregnancy, pain abdomen, fever, vomiting, nausea, loss of appetite, bowel disturbances, burning micturition, duration of symptoms, temperature, right iliac fossa tenderness, right hypochondrium/ right lumbar tenderness, rebound tenderness, Rovsing's sign, cough tenderness, obturator test, psoas test, diffuse tenderness, bowel sound, guarding and rigidity, palpable mass, hepatomegaly, splenomegaly, free fluid, rectal tenderness, total leucocyte count, USG appendix size, USG periappendiceal fluid, position of appendix, treatment received, treatment outcome, length of hospital stay and histopathological findings. Results on continuous measurements were presented on Mean \pm SD (Min - Max) and results on categorical measurements were presented in number (\%). SPSS version 21 was used for the analysis. The approval of the RIMS Research Ethics Board was taken. There was no conflict of interest.

\section{RESULTS}

Majority of the patients were from the age group of 18 to 29 years of age, which consisted $76.5 \%$ of cases. The mean age group of the patients is 26.88 with the standard deviation of 5.28. Majority of the patients comprising of $82.4 \%$ were the resident of urban area. $58.8 \%$ were in the second trimester of pregnancy during the attack of acute appendicitis followed by first $(29.4 \%)$ and third (11.8\%) trimester respectively. 7 patients $(41.17 \%)$ presented with typical migratory pain abdomen and 10 patients (58.83\%) presented with atypical pain abdomen. In seven cases $(41.2 \%)$ there was history of fever and 8 cases (47.1\%) gave a history of vomiting with varying frequency. Nausea was present in 14 cases $(82.4 \%)$ and loss of appetite was present in 12 cases (70.6\%). There were 4 cases $(23.5 \%)$ with the history of burning micturition. 13 patients $(76.5 \%)$ had a temperature between $98-100^{\circ} \mathrm{F}$. Right Iliac Fossa (RIF) tenderness was present in 16 patients (94.1\%), 1 patient (5.88\%) presented with right lumbar (RL) tenderness and one patient $(5.88 \%)$ had both RIF and RL 
tenderness. Rebound tenderness could be elicited in 11 patients (64.7\%), Rovsing's sign was positive in 5 patients (29.4\%) and 13 patients (76.4\%) had positive cough tenderness. Two patients $(11.8 \%)$ had positive obturator test and 4 patients $(23.5 \%)$ had positive psoas test. Localised guarding and rigidity were present in 5 patients $(29.4 \%)$.

Nine patients (52.9\%) had a Total Leukocyte Count (TLC) above 11,000 and eight patients (47.1\%) had TLC between 4000 - 11,000. Fourteen patients (82.4\%) had appendix diameter between 6 and $10 \mathrm{~mm}$. Two patients (11.8\%) had diameter less than $6 \mathrm{~mm}$ and only one patient (5.9\%) had diameter more than $10 \mathrm{~mm}$.

Ten patients $(58.8 \%)$ stayed in the hospital between 5 and 8 days. Five patients (29.4\%) stayed for less than 5 days and 2 patients $(11.8 \%)$ stayed for more than 8.

\begin{tabular}{|c|c|c|c|}
\hline \multicolumn{2}{|c|}{ Presenting Symptoms } & No. of Patients (n= 17) & \% \\
\hline \multirow{2}{*}{$\begin{array}{c}\text { Pain } \\
\text { abdomen }\end{array}$} & Typical & 7 & \multirow{2}{*}{100.0} \\
\cline { 2 - 4 } & Atypical & 10 & 41.2 \\
\hline \multicolumn{2}{|c|}{ Fever } & 7 & 47.1 \\
\hline \multicolumn{2}{|c|}{ Vomiting } & 8 & 82.4 \\
\hline \multicolumn{2}{|c|}{ Nausea } & 14 & 70.6 \\
\hline \multicolumn{2}{|c|}{ Loss of appetite } & 12 & 11.8 \\
\hline Bowel disturbances & 2 & 23.5 \\
\hline Burning micturition & 4 & \\
\hline \multicolumn{2}{|c|}{ Table 1. Table showing Presenting Symptoms } \\
\hline
\end{tabular}

\begin{tabular}{|c|c|c|c|c|c|c|}
\hline \multirow[b]{2}{*}{$\begin{array}{l}\text { Duration of } \\
\text { Symptoms }\end{array}$} & \multicolumn{2}{|c|}{$<12$ Hours } & \multicolumn{2}{|c|}{12 - 24 Hours } & \multicolumn{2}{|c|}{$>24$ Hours } \\
\hline & $\begin{array}{c}\text { No. of } \\
\text { Patient } \\
(n=17)\end{array}$ & $\%$ & $\begin{array}{c}\text { No. of } \\
\text { Patient } \\
(n=17)\end{array}$ & $\%$ & $\begin{array}{c}\text { No. of } \\
\text { Patient } \\
(n=17)\end{array}$ & $\%$ \\
\hline $\begin{array}{c}\text { Pain } \\
\text { abdomen }\end{array}$ & 6 & 35.3 & 3 & 17.6 & 8 & 47.1 \\
\hline Fever & 2 & 28.57 & 0 & 0.0 & 5 & 71.42 \\
\hline Vomiting & 5 & 62.5 & 0 & 0.0 & 3 & 37.5 \\
\hline Nausea & 5 & 35.7 & 3 & 21.4 & 6 & 42.9 \\
\hline $\begin{array}{c}\text { Loss of } \\
\text { appetite }\end{array}$ & 4 & 33.3 & 0 & 0 & 8 & 66.7 \\
\hline $\begin{array}{c}\text { Bowel } \\
\text { disturbance }\end{array}$ & 0 & 0.0 & 0 & 0.0 & 2 & 100.0 \\
\hline $\begin{array}{c}\text { Urinary } \\
\text { disturbance }\end{array}$ & 1 & 25.0 & 0 & 0.0 & 3 & 75.0 \\
\hline
\end{tabular}

Table 2. Showing the duration of the Presenting Symptoms

\begin{tabular}{|c|c|c|}
\hline Clinical Signs & No. of Patients (n= 17) & $\mathbf{\%}$ \\
\hline RIF tenderness & 16 & 94.1 \\
\hline RHC/ RL tenderness & 2 & 11.8 \\
\hline Rebound tenderness & 11 & 64.7 \\
\hline Rovsing's sign & 5 & 29.4 \\
\hline Cough tenderness & 13 & 76.5 \\
\hline Obturator test & 2 & 11.8 \\
\hline Psoas test & 4 & 23.5 \\
\hline Diffuse tenderness & 0 & 0.0 \\
\hline Bowel sound & 17 & 100.0 \\
\hline Guarding and rigidity & 5 & 29.4 \\
\hline Palpable mass & 1 & 5.9 \\
\hline Hepatomegaly & 0 & 0.0 \\
\hline Splenomegaly & 0 & 0.0 \\
\hline Free fluid & 1 & 5.9 \\
\hline Rectal tenderness & 2 & 11.8 \\
\hline \multicolumn{2}{|c|}{ Table 3. Showing Clinical Signs } \\
\hline \multicolumn{2}{|c}{} \\
\hline \multicolumn{2}{|c|}{} \\
\hline
\end{tabular}

\begin{tabular}{|c|c|c|}
\hline Treatment Outcome & No. of Patients & $\%$ \\
\hline Uneventful & 16 & 94.1 \\
\hline Appendicular abscess & 1 & 5.9 \\
\hline Total & 17 & 100.0 \\
\hline \multicolumn{3}{|c|}{ Table 4. Showing treatment outcome of the Patient } \\
\hline
\end{tabular}

\begin{tabular}{|c|c|c|}
\hline Length of Hospital Stay (Days) & No. of Patients & $\%$ \\
\hline$<5$ & 5 & 29.4 \\
\hline $5-8$ & 10 & 58.8 \\
\hline$>8$ & 2 & 11.8 \\
\hline Total & 17 & 100.0 \\
\hline \multicolumn{2}{|c|}{ Table 5. Showing the Length of Hospital Stay } \\
\hline
\end{tabular}

\section{DISCUSSION}

Appendicitis is the most common acute abdominal condition requiring surgery during pregnancy.9,19 The incidence is about 1 in every 1500 pregnancies. 4,5,6 It is most frequent in the second and third decades. The present prospective series consists of 17 patients aged 18 to 39 years with a mean age of $26.88 \pm 5.8$ years, which was consistent with the findings of Popkin et $\mathrm{al}^{13}$ where twenty-three gravid patients ranging in age from 17 to 39 years (mean age $26 \pm 7$ ) underwent appendicectomies. Similarly, 16 patients had laparoscopic appendicectomy at term pregnancy with mean age group of $26.3 \pm 5.3$ in the study done by Affleck DG et al. ${ }^{22}$

In our study, majority of the patients $(58.8 \%)$ were in the second trimester of pregnancy during the attack of acute appendicitis followed by first (29.4\%) and third (11.8\%) trimester respectively as found out by Andersson RE et al ${ }^{7}$ and Barloon TJ et al. ${ }^{18}$ Several authors 7,18 have indicated that acute appendicitis is more prevalent in the first two trimesters, which was also suggested by our study. In this study, there was a preponderance of appendicitis in the second trimester like the findings noted by Andersen $\mathrm{B}$ et $\mathrm{al}^{5}$ and Yilmaz et al;20 however, larger series indicate an equal distribution throughout pregnancy. ${ }^{5}$ Andersson et al 7 also suggested that pregnancy reduces the incidence of acute appendicitis, especially during the third trimester.

In the series of Kyo Keun Lim and colleagues, ${ }^{19}$ eleven patients had pain in the right lower quadrant of the abdomen among 16 patients with surgically proved acute appendicitis: nine $(90 \%)$ of 10 patients in the first trimester of gestation, two $(50 \%)$ of four patients in the second trimester and none of two patients in the third trimester. But this study showed the highest prevalence in the first trimester of pregnancy unlike our study.

Despite the classic obstetrical teaching that appendiceal pain in the pregnant woman migrates laterally and superiorly toward the right upper quadrant,11,12 the location of pain in our series was most common in the right lower quadrant regardless of the gestational age. This finding was consistent with the reports of Hodjati and Kazerooni, ${ }^{12}$ Yilmaz at al ${ }^{20}$ and Kumamoto $\mathrm{K}$ et al. ${ }^{23}$

Some authors have reported that physical examination on presentation is the most reliable diagnostic tool for appendicitis and may reveal fever, increased pulse rate, rebound tenderness and guarding and rectal tenderness. ${ }^{3,4}$ In our series, majority of the patients had rebound tenderness at the admission, only 5 patients had tachycardia and less than half of the patients gave the history of fever. Only 2 patients had rectal tenderness, thus asserting that findings of physical examination are less obvious during pregnancy and could 
explain our long duration of observation before surgery, which was consistent with the findings of Yilmaz et al. ${ }^{20}$

Physiological leukocytosis in pregnancy makes interpretation of the WBC difficult. ${ }^{4}$ In this study leukocytosis was present in more than half of the patients, which was also seen in the study carried out by Yilmaz et al.20

Right iliac fossa tenderness (94.1\%) and rebound tenderness $(64.7 \%)$ were present in the majority of the patients in our study. There was a palpable mass in only 1 patient (5.9\%), which turned out to be an appendicular abscess in our study.

Although, Al-Qudah et $\mathrm{al}^{24}$ have reported that the diagnostic delay does not alter the outcome in the third trimester and does not cause foetal loss, most of the reports have increased rates of spontaneous abortion, preterm contraction and preterm labour in patients with perforated appendicitis and advanced gestational age.20 Additionally, most of the reports have shown that there is a higher risk of perforation with increased gestational age ${ }^{13}$; however, our study did not reveal any data consistent with these investigations as found by Yalmaz et al. ${ }^{20}$

A rapid, reliable and accurate imaging method is needed to aid in the evaluation of pregnant women with acute rightlower-quadrant pain, because clinical and laboratory findings cannot be used to reliably confirm or dismiss a diagnosis of acute appendicitis in these patients. 5,6 So, the ideal imaging method should be able to aid in the diagnosis and to rule out other possible causes of right lower quadrant pain. Many studies demonstrate that high-resolution, graded compression sonography is useful in the evaluation of pregnant patients suspected of acute appendicitis. ${ }^{18,25,26}$ Traditionally, ultrasonography (USG) has been the initial imaging modality of choice in the evaluation of obstetric patients, because it is safe and inexpensive and can be performed easily at the bedside.5,6 USG, when read as positive, requires no further confirmatory test other than surgery. ${ }^{27}$ Thus, as suggested by many previous studies, we adopted ultrasonography as the initial choice of imaging and diagnosed the case as acute appendicitis when the USG identified the appendix as non-compressible blind-ended tubular structure in the right lower quadrant with maximum diameter greater than $6 \mathrm{~mm}$, also adopted by Barloon TJ et al 18 and Hyo Keun Lim et al. ${ }^{19}$

Fifteen out of seventeen patients in our study showed appendix size more than $6 \mathrm{~mm}$. Out of these patients 6 patients underwent appendicectomy and only 1 out of 6 cases who had appendicectomy in first or second trimester showed normal appendix in the histopathological examination proving that USG is highly specific in diagnosis of acute appendicitis. Lim et $\mathrm{al}^{19}$ have reported that the accuracy of ultrasound for the diagnosis of appendicitis is very high (98\%). And Yilmaz et $\mathrm{al}^{20}$ found that the rate of accuracy for abdominal ultrasound to confirm the diagnosis of appendicitis in pregnancy was $50 \%$, because the ultrasound examinations were performed by radiologists without surveillance of a specialist.

Our data also support the use of ultrasonography in pregnancy showing a statistically significant reduction in the negative appendicectomy rate also found by Wallace CA et al. ${ }^{26}$

Previous studies has also shown that in pregnant women, graded-compression USG has been shown to be accurate in the first and second trimesters, but technically difficult in third trimester. By using the graded-compression technique with the patient in the left posterior oblique or left lateral decubitus position proved to be helpful in this situation. ${ }^{19}$

If USG is non-diagnostic further imaging (CT/ MRI) may avoid a negative appendicectomy, which has been associated in prior studies with a significant incidence of foetal demise. 27 In the study conducted by Kumamoto $\mathrm{K}$ et al,23 24 patients (72.7\%) were diagnosed with acute appendicitis using USG, while nine patients $(27.3 \%)$ failed to show preoperative findings in the appendix. As a consequence, those patients underwent CT examination, resulting in a diagnosis of acute appendicitis. Freeland et $\mathrm{al}^{27}$ demonstrated that CT or Magnetic Resonance Imaging (MRI) is recommended as an additional examination if USG fails to be diagnostic in pregnant patients. Franca NA et al 28 found that the clinical manifestations of appendicitis are similar to non-pregnant women, however, without a classic presentation which often occurs diagnosis is difficult and must be supported by imaging. In another study conducted by Cobben LP et al,29 sonography could not depict the appendix in 11 of 12 patients, partly because of obesity and partly because of the large gravid uterus making the graded compression technique more difficult, especially when the appendix is in a retrocaecal position. CT can be performed in such cases, but it involves a considerable amount of radiation. To their knowledge, no delayed sequelae from undergoing or performing MRI have been encountered and it is expected that the risk of delayed sequelae is extremely low. CT is of limited use in obstetric patients, because of concerns about radiation-induced teratogenesis.

Laparotomy in pregnant patients is also associated with increased foetal morbidity and mortality. This has led to reluctance of surgeons to intervene early in the course of the disease. 18 In our study 11 patients (64.7\%) were managed conservatively and 6 patients (35.3\%) underwent open appendicectomy. One patient $(5.9 \%)$ in the non-operative group developed appendicular abscess, which was later drained by percutaneous pigtail drainage.

In two patient cases studied by Young $\mathrm{BC}$ et al,30 they suggest that non-surgical management of ruptured appendicitis in pregnancy is possible and warrants further study to fully elucidate the risks and outcomes to the patient and her foetus.

Although, negative laparotomy rates during pregnancy range from 15 to $50 \%$ in literature, it was determined to be $4 \%$ in study done by Yilmaz et al. ${ }^{20}$ Zingone $\mathrm{F}$ et $\mathrm{al}^{31}$ found that the highest and the lowest rate of negative appendectomies were in the second and third trimesters respectively.

\section{CONCLUSION}

The rate of appendicitis is highest in the second trimester followed by the first and third trimester. Infected appendix appears more likely to rupture during pregnancy, especially in the third trimester, possibly because of delay in diagnosis and intervention which warrants the need of early diagnosis and definite surgery. The symptoms and signs are not reliable, but only magnify the diagnostic difficulty. Abdominal findings (guarding and rigidity) during pregnancy may be less prominent than in non-pregnant women, because the gravid uterus lifts and stretches the anterior abdominal wall 
away from the inflamed appendix which may mask the local signs. In addition to ultrasonography, magnetic resonance imaging may be done in cases of inconclusive diagnosis. When the diagnosis is relatively certain, appendicectomy is recommended through an incision at McBurney's point. Maternal morbidity following appendicectomy is low, except in patients in whom the appendix has perforated. In spite of risk to the foetus following appendicectomy, the long-term prognosis for women who undergo appendicectomy during pregnancy seems to be good.

\section{REFERENCES}

[1] Williams GR. Presidential address: a history of appendicitis. With anecdotes illustrating its importance. Ann Surg 1983;197(5):495-506.

[2] Fitz RH. Perforating inflammation of the vermiform appendix, with special reference to its early diagnosis and treatment. Trans Assoc Am Physicians 1886;1:107-44.

[3] Tamir IL, Bongard FS, Klein SR. Acute appendicitis in the pregnant patient. Am J Surg 1990;160(6):571-6.

[4] Sharp HT. Gastrointestinal surgical conditions during pregnancy. Clin Obstet Gynecol 1994;37(2):306-15.

[5] Andersen B, Nielsen TF. Appendicitis in pregnancy: diagnosis, management and complications. Acta Obstet Gynecol Scand 1999;78(9):758-62.

[6] Mourad J, Elliott JP, Erickson L, et al. Appendicitis in pregnancy: new information that contradicts long-held clinical beliefs. Am J Obstet Gynecol 2000;182(5):1027-9.

[7] Andersson RE, Lambe M. Incidence of appendicitis during pregnancy. Int J Epidemiol 2001;30(6):1281-5.

[8] Bickell NA, Aufses AH Jr, Rojas M, et al. How time affects the risk of rupture in appendicitis. J Am Coll Surg 2006;202(3):401-6.

[9] Weingold AB. Appendicitis in pregnancy. Clin Obstet Gynecol 1983;26(4):801-9.

[10] Oto A, Srinivasan PN, Ernst RD, et al. Revisiting MRI for appendix location during pregnancy. Am J Roentgenol 2006;186(3):883-7.

[11] Pates JA, Avendiano TC, Zaretsky MV, et al. The appendix in pregnancy: confirming historical observations with a contemporary modality. Obstet Gynecol 2009;114(4):805-8.

[12] Hodjati H, Kazerooni T. Location of the appendix in the gravid patient: a re-evaluation of the established concept. Int J Gynaecol Obstet 2003;81(3):245-7.

[13] Popkin CA, Lopez PP, Cohn SM, et al. The incision of choice for pregnant women with appendicitis is through McBurney's point. Am J Surg 2002;183(1):202.

[14] Cunningham FG, McCubbin JH. Appendicitis complicating pregnancy. Obstet Gynecol 1975;45(4):415-20.
[15] McGee TM. Acute appendicitis in pregnancy. Aust N Z J Obstet Gynaecol 1989;29(4):378-85.

[16] Sivanesaratnam V. The acute abdomen and the obstetrician. Bailliere's Best Pract and Res in Clin Obstet Gynaecol 2000;14(1):89-102.

[17] Bailey LE, Finley RK Jr, Miller SF, et al. Acute appendicitis during pregnancy. Am Surg 1986;52(4):218-21.

[18] Barloon TJ, Brown BP, Abu-Yousef MM, et al. Sonography of acute appendicitis in pregnancy. Abdom Imaging 1995;20(2):149-51.

[19] Lim HK, Bae SH, Seo GS. Diagnosis of acute appendicitis in pregnant women: value of sonography. Am J Roentgenol 1992;159(3):539-42.

[20] Yilmaz HG, Akgun Y, Bac B, et al. Acute appendicitis in pregnancy - risk factors associated with principal outcomes: a case control study. Int J Surg 2007;5(3):192-7.

[21] Viktrup L, Hée P. Fertility and long-term complications four to nine years after appendicectomy during pregnancy. Acta Obstet Gynecol Scand 1998;77(7):746-50.

[22] Affleck DG, Handrahan DL, Egger MJ, et al. The laparoscopic management of appendicitis and cholelithiasis during pregnancy. Am J Surg 1999;178(6):523-9.

[23] Kumamoto K, Imaizumi H, Hokama N, et al. Recent trend of acute appendicitis during pregnancy. Surg Today 2015;45(12):1521-6.

[24] Al-Qudah MS, Amr M, Sroujieh A, et al. Appendicectomy in pregnancy: the experience of a university hospital. J Obstet Gynecol 1999;19(4):3624.

[25] Pedrosa I, Zeikus EA, Levine D, et al. MR imaging of acute right lower quadrant pain in pregnant and nonpregnant patients. Radiographics 2007;27(3):721-43.

[26] Wallace CA, Petrov MS, Soybel DI, et al. Influence of imaging on the negative appendicectomy rate in pregnancy. J Gastrointest Surg 2008;12(1):46-50.

[27] Freeland M, King E, Safcsak K, et al. Diagnosis of appendicitis in pregnancy. Am J Surg 2009;198(6):753-8.

[28] Neto FAH, Amorim MM, Nóbrega BM. Acute appendicitis in pregnancy: literature review. Rev Assoc Med Bras 2015;61(2):170-7.

[29] Cobben LP, Groot I, Haans L, et al. MRI for clinically suspected appendicitis during pregnancy. Am J Roentgenol 2004;183(3):671-5.

[30] Young BC, Hamar BD, Levine D, et al. Medical management of ruptured appendicitis in pregnancy. Obstet Gynecol 2009;114(2 Pt 2):453-6.

[31] Zingone F, Sultan AA, Humes DJ, et al. Risk of acute appendicitis in and around pregnancy: a populationbased cohort study from England. Ann Surg 2015;261(2):332-7. 